\title{
Modeling foraging in the northern anchovy (Engraulis mordax): individual behavior can predict school dynamics and population biology
}

\author{
Peter Nonacs, Paul E. Smith, and Marc Mangel
}

\begin{abstract}
Many economically important oceanic fishes travel in large schools, but the foraging behaviors of these schools and the life history consequences of these behaviors have rarely been addressed. The availability of extensive information on bioenergetics of the northern anchovy (Engraulis mordax) allows us to use this species as a case study. We modeled two types of potential behavior that fish could use to exploit a patchy environment: (i) maximizing growth rate or (ii) maximizing survivorship to adulthood and reproduction, which is a function of both growth and avoiding predation. Patterns from existing data sets on gut contents and growth rates from the field for juvenile E. mordax were consistent only with the prediction of maximizing survivorship. The model makes further testable predictions about $(i)$ expected swimming velocities between zooplankton patches, (ii) patterns of size segregation in the formation of schools, (iii) the proportion of zooplankton patches that schools consume, and (iv) reactions to decreases in environmental quality. Overall, the model predicts that anchovies spend at least $25 \%$ of their time in schools that are too large to be energetically economical and suggests further research on several variables that could affect populations of schooling fishes.
\end{abstract}

Résumé : De nombreaux poissons d'importance commerciale se déplacent en grands bancs, mais le comportement de recherche de nourriture de ces bancs et les conséquences de ce comportement sur le cycle vital ont rarement été étudiés. La disponibilité d'information détaillée sur la bioénergétique de l'anchois du Pacifique (Engraulis mordax) nous a permis d'utiliser cette espèce dans une étude de cas. Nous avons modélisé deux types de comportement potentiel que le poisson peut utiliser pour exploiter un milieu inégal, soit : (i) maximiser son taux de croissance ou (ii) maximiser sa survie jusqu' au stade adulte et à la reproduction, ce qui est fonction de la croissance et de l'évitement de la prédation. Les tendances dans les séries de données disponibles sur les contenus stomacaux et les taux de croissance des juvéniles de E. mordax, données recueillies sur le terain, ne correspondaient qu'à l'hypothèse de la maximisation de la survie. Le modèle fait d'autres prédictions vérifiables sur : (i) la vitesse prévue de nage entre les nuées de zooplancton, (ii) les tendances de la répartition par taille dans la formation des bancs, (iii) la proportion des nuées de zooplancton que les bancs consomment et (iv) les réactions à une baisse de la qualité de l'environnement. En général, le modèle prédit que l'anchois passe au moins $25 \%$ de son temps en bancs trop gros pour être efficaces au plan énergétique et indique d'autres pistes de recherche sur plusieurs variables qui pourraient influer sur les populations de poissons se déplaçant en bancs.

[Traduit par la Rédaction]

\section{Introduction}

Oceanic schooling fishes are a vital resource for human populations, and for this reason alone there should be considerable

Received April 15, 1997. Accepted October 21, 1997.

J13967

P. Nonacs. ${ }^{1}$ Department of Biology, 621 Circle Dr. South, University of California, Los Angeles, CA 90095, U.S.A.

P.E. Smith. Southwest Fisheries Science Center, La Jolla Laboratory, National Marine Fisheries Service, NOAA, La Jolla, CA 92038, U.S.A.

M. Mangel. Department of Environmental Studies and Institute of Marine Sciences, University of California, Santa Cruz, CA 95064, U.S.A.

1 Author to whom all correspondence should be addressed. e-mail: PNonacs@biology.ucla.edu interest in understanding their behavior and responses to environmental changes (Gates 1993). To predict the population consequences of a particular set of environmental conditions, we need to connect the fishes' behavioral response to their physical surroundings. Although parameters such as prey abundance, water temperatures, school sizes, and biomass of stocks have often been measured or estimated, less is known about the interaction between foraging tactics, growth, and survivorship. As a starting point, we can construct a predictive foraging model based on data covering a species in its natural environment. Such models have an excellent track record of both explaining the functional bases for observed behaviors and identifying key variables that need future study (Stephens and Krebs 1986; Mangel and Clark 1988). An excellent species among schooling fish for such an approach is the northern anchovy (Engraulis mordax). There is a wealth of natural historical data that includes the bioenergetics of swimming and feeding (Blaxter and Hunter 1982; Butler 1989; Boggs 1991), 
schooling behavior, feeding methods, and diet (Blaxter and Hunter 1982), and patchiness of its prime prey item, zooplankton (Koslow 1981; Star and Mullin 1981; Smith et al. 1989).

Nonacs et al. (1994) constructed behavioral and population models of E. mordax living in the California Current. Although their model predicted a life history trade-off of reduced growth for reduced predation rate, it was based on a single school size (i.e., the "average" school). In general, however, anchovies live in schools that are much larger the average size. The mean diameter across all schools is $29.1 \mathrm{~m}$, but over half the population of anchovies are in schools of diameter $>70 \mathrm{~m}$ (Smith 1981). Schooling in fishes can increase survivorship by diminishing detection by predators (Brock and Riffenburgh 1960; Swartzman 1991) and confusing predators by complex coordinated maneuvers (Eshel 1978). However, an upper limit to school size must be set by the spatial distribution of food and productivity of the habitat (Duffy and Wissel 1988).

Using state variable dynamic models (see Mangel and Clark 1988), we examine anchovies behaving in one of two broadly defined ways: (i) strictly maximizing growth rate, which is equivalent to maximizing the net rate of calorie intake over time, or (ii) maximizing lifetime egg production, which often can require a trade-off between feeding in zooplankton patches (which increases fish size and therefore fecundity) and reducing predation rates (which are assumed to be highest in the zooplankton patches). Thus, the behavior of energy-maximizing animals will not be affected by predation risk, while animals that maximize lifetime reproduction will often exhibit predation risk sensitive behavior. That fish are capable of a growth rate/predation risk trade-off has been experimentally demonstrated in a wide array of species (e.g., Werner et al. 1983; Dill and Fraser 1984; Abrahams and Dill 1989; Fraser and Gilliam 1992). Further model predictions include the maximum size of E. mordax schools able to capture enough food to maintain a positive energy balance and the consequences of depleted food resources on growth and behavior.

\section{Methods}

The summary points of our model are the following. (i) Zooplankton are found in high densities in discrete patches in the ocean (Koslow 1981; Star and Mullin 1981). These patches are taken as circular and anchovies feed by biting at zooplankters. (ii) Between patches, there are no large zooplankters and the fish feed only by filtering small zooplankton and phytoplankton. (iii) In the zooplankton patches, fish can be up to 20 times more susceptible to predation per unit of time than they are between the patches. We do not specify the mechanism that increases the predation risk. (Potential factors that could increase susceptibility to predation could include loss in tactical evasion ability due to inattentiveness while feeding, increased range at which predators can detect the school due to wider spacing of individuals, uncoordinated movements of feeding fish drawing attention, or the inability to effectively respond to attacks due lowered school cohesion.) (iv) As they grow, fish become less vulnerable to predators. (v) Schools encounter zooplankton patches randomly. The average patch has a radius of $634 \mathrm{~m}$ and the average gap between patches is $2553 \mathrm{~m}$ (Smith et al. 1989).

Specifically, in the model the size range of fish is $5-12.98 \mathrm{~cm}$, with steps of $0.02 \mathrm{~cm}$. This far exceeds the size range of late juveniles so as to eliminate "edge" effects from the model (i.e., if a fish is constrained such that it cannot grow larger than $8.5 \mathrm{~cm}$, then as it approaches that size, feeding will be artifactually devalued because further growth is not possible). We use caloric expenditures in E. mordax as measured by Boggs (1991) such that basal metabolism $=0.4683 L^{2.4} \mathrm{cal} /$ day and swimming metabolism $=$ $0.00094 L^{2.14} v^{1.44} \mathrm{cal} / \mathrm{h}$ where $L$ is length (centimetres) and $v$ is swimming velocity (centimetres per second).

The behaviors of the fish that we consider are how fast they swim both between patches and inside the patches. The rate of swimming between patches $\left(v_{0}\right)$ directly determines the rate at which new patches are encountered. The range of swimming velocities between patches is $1-59 \mathrm{~cm} / \mathrm{s}$. Anchovies filter-feed for a third of the time they are swimming between patches, and it is assumed that they swim at a constant rate of $10 \mathrm{~cm} / \mathrm{s}$ while filter-feeding. Thus, the average rate of swimming between patches $\left(=\left(10+2 v_{0}\right) / 3\right)$ has a range of $4-42.7 \mathrm{~cm} / \mathrm{s}$. Blaxter and Hunter (1982) found that faster-moving schools were more elongate. From their relationship, the width of a school is estimated to be $25.3 A^{0.5} v_{0}^{-0.42} \mathrm{~m}$ where $A$ is the surface area of the school. The faster a school swims, the smaller is the volume of water experienced by the school (i.e., more fish will swim through the same water). Therefore, moving rapidly between patches reduces the gain (averaged for all fish in the school) from filter-feeding. Spacing between fish, the density of microplankton between patches, and the stomach capacity of fish are all constants in this model and are given values that are estimated from the field (Nonacs et al. 1994). Fish at the front of a moving school have been observed to feed more than those in the rear (Krause 1993; DeBlois and Rose 1996), but it is assumed that the leading fish will change over time with perhaps the hungriest leading the schools (see Krause 1993).

A zooplankton patch is assumed to occupy a cylindrical volume with a depth of $10 \mathrm{~m}$ and a radius of $634 \mathrm{~m}$ (Smith et al. 1989). A fish school upon encountering a zooplankton patch expands to fill the entire volume with an equal number of fish per cubic metre and, after feeding, contracts to its original size and exits the patch in a randomly chosen direction (such as for Atlantic cod (Gadus morhua), see DeBlois and Rose 1995). Therefore, the average distance a fish from a school travels in entering and exiting a patch is equal to twice the average chord length of the circular surface area of the patch, which is 2.401 times the radius of the patch. This is the minimum distance a fish swims in a food patch if it swims only in straight lines. However, it is likely that a fish's movement will have both a forward component $\left(v_{\mathrm{f}}\right.$ : to move through the patch) and a lateral movement component ( $v_{\mathrm{s}}$ : to search for prey). The true velocity of the fish in the patch is a function of both: $v_{\mathrm{p}}=\left(v_{\mathrm{f}}^{2}+v_{\mathrm{s}}^{2}\right)^{1 / 2}$. The model allows fish to choose integer values of $v_{\mathrm{f}}$ and $v_{\mathrm{s}}$, subject to the constraint that $v_{\mathrm{p}} \leq 50 \mathrm{~cm} / \mathrm{s}$. The actual time fish spend in a patch is directly proportional to $v_{\mathrm{f}}$, which has a minimum value of $1 \mathrm{~cm} / \mathrm{s}$ (i.e., all schools eventually do leave patches).

The anchovy-zooplankton expected time to encounter within a patch $(Z)$ is determined by a Gerritsen-Strickler equation (Gerritsen and Strickler 1977) such that

$$
\left.Z=1+2 /\left\{R^{2} d / 3\right)\left[\left(u^{2}+3 v_{\mathrm{p}}^{2}\right) / v_{\mathrm{p}}\right]\right\} \mathrm{s}
$$

where $R$ is the reactive distance of the fish, $d$ is the density of zooplankton (number per cubic metre), and $u$ and $v_{\mathrm{p}}$ are the swimming velocities of the zooplankton and fish, respectively $\left(v_{\mathrm{p}}>u=5 \mathrm{~cm} / \mathrm{s}\right.$, the swimming velocity of a copepod). The model assumes a $50 \%$ failure rate per encounter due to either the prey escaping or interference with other fish in the school plus a 1-s handling time per prey. Interference between foraging fish is likely to increase with fish density, but the model's results are not very sensitive to a wide range of capture efficiencies (Nonacs et al. 1994). The energetic cost of capturing a prey item is calculated as the cost of swimming at a velocity that captures a prey item swimming directly away from an approaching anchovy $1 \mathrm{~s}$ after it enters the fish's reactive distance. The $R$ is best estimated from numerous studies on other species (see Nonacs 
et al. 1994) as equal to $13.4 x L$ where $x$ and $L$ are the lengths (centimetres) of the prey item and the anchovy.

Note that hunger or gut fullness in the anchovies is not a state variable in this model. This is not to say that hunger does not motivate fish behavior. However, in our model, swimming velocity directly determines patch encounter rates (i.e., a hungry fish could alter its swimming speed). Therefore, having a hunger state variable would be redundant to our swimming speed variables. We also assume that the fish's habitat is globally nondepleting. Therefore, the consumption of an encountered patch does not reduce the likelihood of future patch encounters. This is equivalent to assuming a steady state where the rate of blooming of new zooplankton patches equals the rate at which they are being consumed.

The model translates captured prey into calories accumulated and available for growth. Assimilation efficiency (65\%) and stomach emptying rates ( $\mathrm{e}^{-0.106 t}$ where $t$ is the time (hours) since the food was ingested) are estimated from direct measurements by Boggs (1991) on captive $E$. mordax. Nonacs et al. (1994) analyzed the sensitivity of the model to errors in these estimates and found that the predictions were robust to a large range of values. Therefore, we do not vary these values in this paper. If fish reached satiation (i.e., completely filled their stomachs), feeding rate was constrained to be no greater than the emptying rate. In practice, however, the model rarely predicted feeding to satiation (see Results section).

A dynamic state variable model requires estimating a terminal fitness at the endpoint interval being considered. We use a 1-year time interval, with reproduction occurring only in the last 90 days. The terminal fitness function is then the fecundity of the fish, based on a size-fecundity relationship measured from fish caught in the field (Hunter and Leong 1981). Thus, in our model, the fitness of any behavior at any time is defined by its eventual payoff in egg production. We constructed a simplified version of the model for the reproductive period of the last 90 days because of the added complication of investing in eggs versus investing in somatic growth. This model produced a robust result across many assumptions of growth/egg production trade-offs, which is that fitness is linearly related to fish size. From that terminal function, we backward iterated 270 days in 10-day time steps to find the optimal behavioral trajectories for fish of a given size at a given time. Predictions of growth trajectories are derived using forward iterations (Mangel and Clark 1988) for fish that are $6 \mathrm{~cm}$ on day 1 . This time period, both in our model and in the field, appears to encompass the stage known as "late juvenile" (=6-8.5 cm in length: Smith 1985; Butler et al. 1993), which is the dominant size-class in E. mordax (Smith 1985; Nonacs et al. 1994). It is also the size at which complex differentiation and metamorphosis seen in smaller fry no longer occur but at which no reproduction occurs (reproduction is rare in fish under $9 \mathrm{~cm}$ in length: Hunter and Leong 1981). Therefore, the simplification of assuming only somatic growth for the first 180 days is fully justified.

Thus, fitness is defined as a function of the size the fish achieves through growth multiplied by the probability of surviving to reproduction. The survival probability is a function of size and where the fish spend their time; the daily instantaneous mortality rate (IMR) is

$$
\operatorname{IMR}=0.003 \mathrm{e}^{-a(L-5)}[p(m-1)+1]
$$

where $p$ is the proportion of the day spent inside the zooplankton patch and $m$ measures how much more risky the patch is than the surrounding ocean $(1<m<20), L$ is the length of the fish (centimetres), and $a$ measures the benefit of larger size in reducing mortality (we use $a=0.01$ ). A $6-\mathrm{cm}$ fish that never entered a zooplankton patch would thus have an IMR of close to 0.003 , which is estimated as that of the next larger life stage (Smith 1985; Butler et al. 1993). When $m=1$, a fish is equally at risk inside and outside zooplankton patches. Thus, if $m<1$, then the zooplankton patch will be best both for growth and avoiding predators. The optimal strategy, then, must be the one that maximizes growth rate and will be insensitive to overall predation risk.
A substantial advance in this model from the one in Nonacs et al. (1994) is that here, we include school size variability as observed in nature. To do so, we used five school diameters of 14.5, 28.6, 56.2, 110 , and $217 \mathrm{~m}$, each of which represents the mean school size for $20 \%$ of the population biomass (as cumulative population biomass is plotted against increasing school size: Smith 1981). We assumed that an average fish in any given 10-day time period spends $20 \%$ of its total time in each of the five size-classes of schools. In this model, we do not consider how schools form or break up, and thus do not consider how fish move between schools of different sizes. In a separate analysis, we increased school size for fish of 6 and $8.5 \mathrm{~cm}$ until no possible combination of swimming velocities could maintain a positive energy balance for the average school member. We defined this as the maximum economic school size.

Each of the five school sizes could have different optimal swimming velocities, so that in total, fish make 15 independent behavioral choices of swimming velocities $\left(v_{0}, v_{\mathrm{f}}\right.$, and $v_{\mathrm{s}}$ for each school size) between patches and within patches. With this many variables (with each having at least 49 possible states), it becomes impossible to examine every possible combination of swimming velocities across all school sizes. Therefore, initially, we made a series of random guesses regarding possible combinations of swimming velocities (in step sizes of $5 \mathrm{~cm} / \mathrm{s}$ ) across the various school sizes. After 10000 such guesses, we restricted the search for optimal values to the area around the best guess and a new series of guesses began, with smaller step sizes. After a number of such iterations, the region surrounding the best guess was rigorously examined. This methodology was repeated several times for the same starting conditions and the optima converged across runs. This indicates that although it is unlikely that the model found the globally optimal set of predicted swimming velocities, it was close to that set and not erroneously climbing local peaks of fitness.

\section{Results}

If zooplankton patches have a radius of $634 \mathrm{~m}$ and an average distance of $2553 \mathrm{~m}$ between patches, the maximum school size that can maintain a positive energy balance has a diameter of 108 or $123 \mathrm{~m}$ for 6- or 8.5-cm fish, respectively. Larger fish can form larger maximum-sized schools because the interfish distances are greater, resulting in fewer fish per cubic metre of water (Graves 1977). Nevertheless, about 25-30\% of E. mordax found in nature (Smith 1981) are in schools that are larger than is energetically economic (Fig. 1). These large-size schools are not able to move through the ocean fast enough (or would expend too much energy moving) to encounter sufficient quantities of zooplankton to maintain a positive energy balance.

Although fish are in negative energy balance in the largest schools, they can maintain rapid growth by compensating in smaller schools. If fish ignore differential predation risk in zooplankton patches and maximize net caloric intake rate $(m=1)$, then we predict a growth rate that appears to be substantially faster than observed in nature (Fig. 2). However, fish that respond to both food and predation risk show a growth rate that is more similar to estimates from the field. The predicted growth rates also decline as the zooplankton patch increases from 2 to 20 times more risky than areas between patches.

Assuming that fish maximize growth rate also produces very different predictions about how fast fish are swimming between patches and within them (Fig. 3). Predation-sensitive behavior predicts across all school sizes, times of year, and fish size a slow rate of swimming between patches (the 
Fig. 1. Cumulative biomass (solid circles) of a northern anchovy population contained in schools of a given diameter or less (from Smith 1981). The curve fit to the relationship is y $=D^{2} /\left(D^{2}+D_{0}^{2}\right)$ where $D$ is the school diameter and $D_{0}$ is a constant (=65). The open circles are the predicted maximum school sizes for fish of length 6 or $8.5 \mathrm{~cm}$ for which energy budgets are positive. School sizes to the right of the broken lines are thus bioenergetically uneconomical.

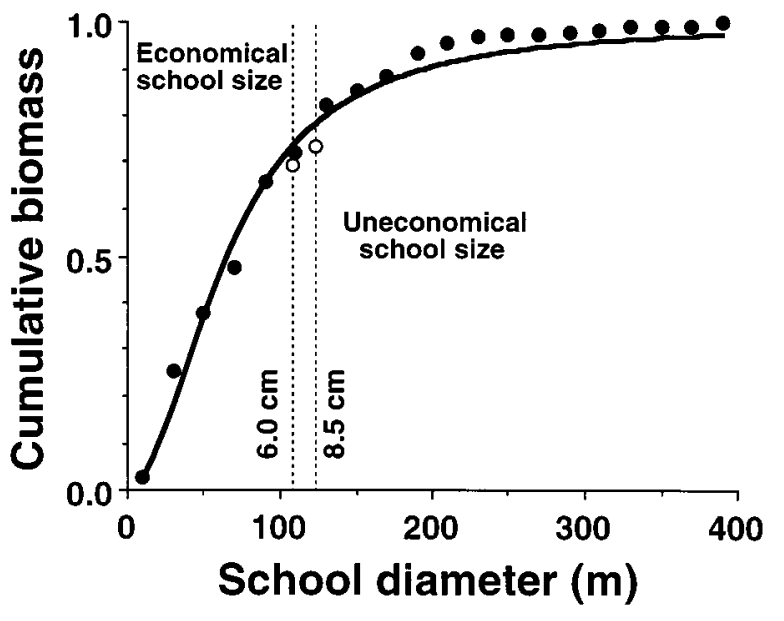

Fig. 2. Predicted growth rates of northern anchovy under an assumption that anchovies are net energy intake rate maximizers or are predation sensitive (with zooplankton patches varying from 2 to 20 times more risky than the surrounding water). The heavy line is the mean size of anchovy juveniles caught in the field as the season progresses (Butler 1989).

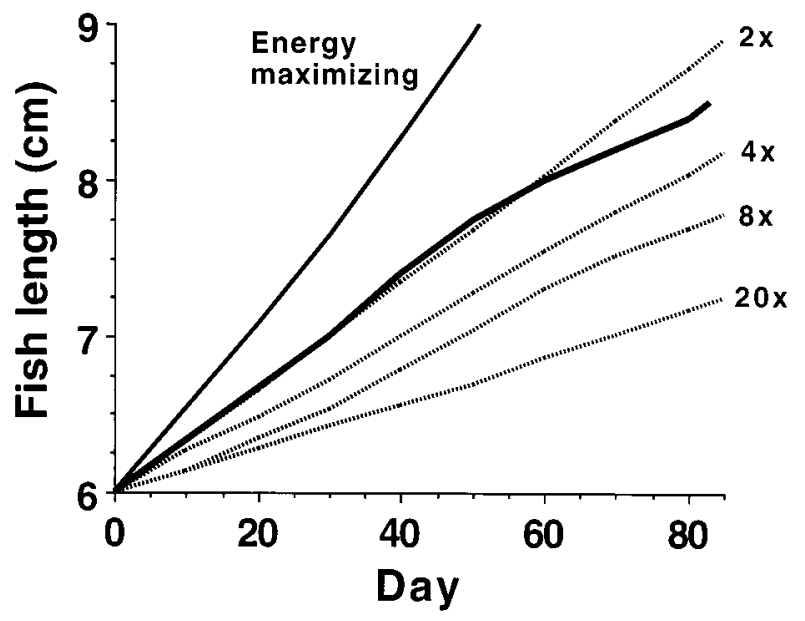

average rate is $<7 \mathrm{~cm} / \mathrm{s}$ ). In contrast, energy-maximizing behavior predicts rapid movement between patches in all school sizes except the largest class. Fish in small schools (the 10 and $30 \%$ size-classes) move between 20 and $30 \mathrm{~cm} / \mathrm{s}$ and in medium schools (50 and 70\%) generally range between 30 and $40 \mathrm{~cm} / \mathrm{s}$.

As the season progesses, predation-sensitive behavior predicts that smaller schools may start moving more quickly between patches, but larger schools remain slow moving. Predation-sensitive behavior also predicts that smaller juveniles $(<7.25 \mathrm{~cm})$ swim more rapidly than larger juveniles $(>7.25 \mathrm{~cm})$. Conversely, energy-maximizing behavior predicts no consistent effect of time or fish size except in the $70 \%$ size-class school where larger fish tend to swim more rapidly than smaller fish.

Both assumptions of fish behavior predicted generally similar behavior in the zooplankton patches, i.e., rapid movement through them. In all cases, predation-sensitive fish move forward as rapidly as possible $\left(v_{\mathrm{f}}=49 \mathrm{~cm} / \mathrm{s}\right.$, the maximum velocity allowed in the model). A wider range of velocities $(33-49 \mathrm{~cm} / \mathrm{s})$ is predicted for energy-maximizing fish in schools in the $70 \%$ or less size-classes. The only exception to the prediction of rapid movement was in the $90 \%$ size-class where the model predicted $v_{\mathrm{f}}$ 's of $3-9 \mathrm{~cm} / \mathrm{s}$.

Energy-maximizing fish will spend more time in zooplankton patches feeding than predation-sensitive fish. This allows us to compare the patch depletion associated with different behaviors (Table 1). Schools in the 50th percentile or greater in size uniformly will consume all the zooplankton. However, predation-sensitive small schools will leave patches that still contain about $40 \%$ of the initial zooplankton population. Energy-maximizing schools will take a far higher proportion.

The assumptions of energy maximization and predation sensitivity thus predict different rates of encounter of zooplankton patches and different levels of exploitation of those patches. This translates into fish having different levels of stomach fullness and, if the population of fish were to be sampled, a different distribution of gut contents. The model allows us to predict the distribution of gut contents as if a hypothetical population were sampled. We generated the expected distributions by estimating the average fish's gut contents at the time it left a zooplankton patch based on the number of prey per fish (which was a function of the school size) and how long it searched in the patches (based on the assumption of either energy maximization or predation sensitivity). The gut is assumed to empty at the rate that Boggs (1991) estimated for fed E. mordax, prorated by the time between patch encounters. The gut is assumed to fill at a linear rate from the minimum content at patch encounter to the previously estimated fullness at departure. We divided this patch encounter/patch use cycle into equal time steps and then randomly sampled 250000 fish in equal proportion across time steps and across the five school size-classes and recorded their gut contents.

This sampling regime assumed that each fish in a school had equal success, but clearly, there is likely to be within-school variability in prey capture rates. To estimate the effect of such variance, we used the estimates of the mean proportion of the gut that was filled at any given time and supplied variance around that mean (assuming a normal distribution of success probabilities). Therefore, we randomly choose a time step in the cycle and then randomly choose a fish from a normal distribution of stomach fullness. (For the sampling regime, we arcsin transformed into degrees the predicted proportion of gut fullness and gave the distribution standard deviations of 10,20 , or 30 degrees.)

The expected distribution of stomach contents (=gut fullness) from a randomly sampled population under an assumption of energy maximization is bimodal, with a large proportion of fish having fairly full stomachs, even when within-school capture success is highly variable (Fig. 4). In 
Fig. 3. Mean predicted velocity of northern anchovy schools of various sizes as a function of fish size and time of season. Predation risk in the zooplankton patches is assumed to be either equal to the surrounding waters or 4 times greater. When the risk is equal, fish act like net energy intake rate maximizers (see text). The percentages correspond to school diameters of $14.5 \mathrm{~m}(10 \%), 28.6 \mathrm{~m} \mathrm{(30 \% ),} 56.2 \mathrm{~m}(50 \%), 110 \mathrm{~m}(70 \%)$, and $217 \mathrm{~m}(90 \%)$.
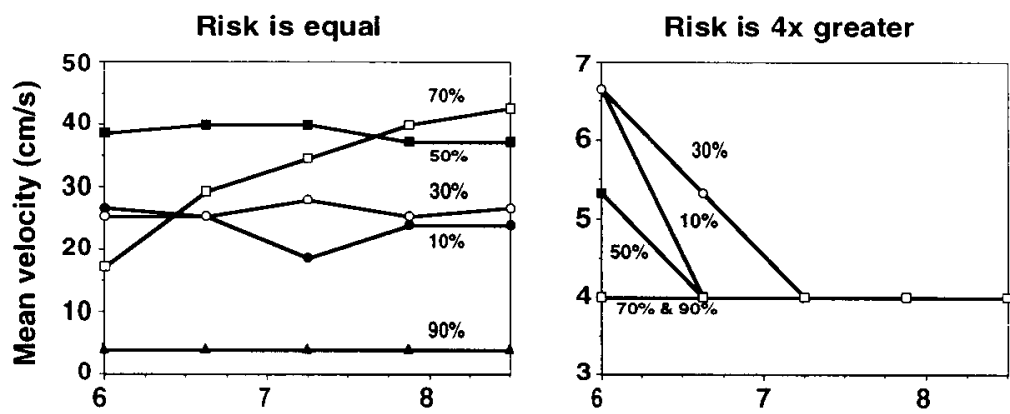

Day $=10$
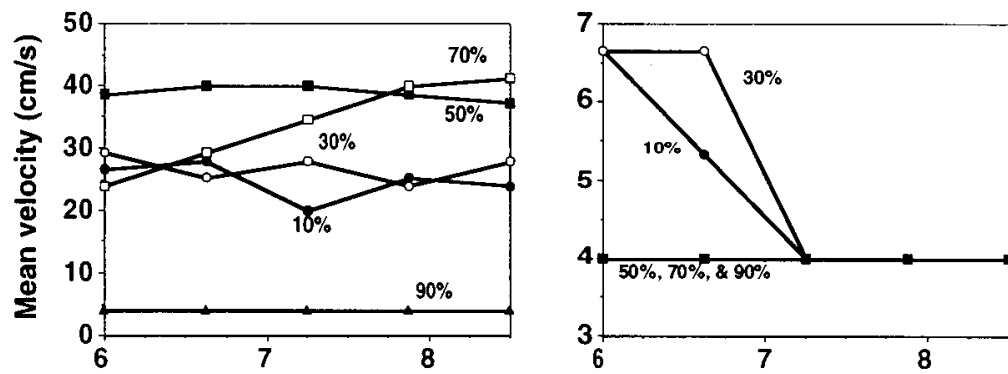

Day $=30$
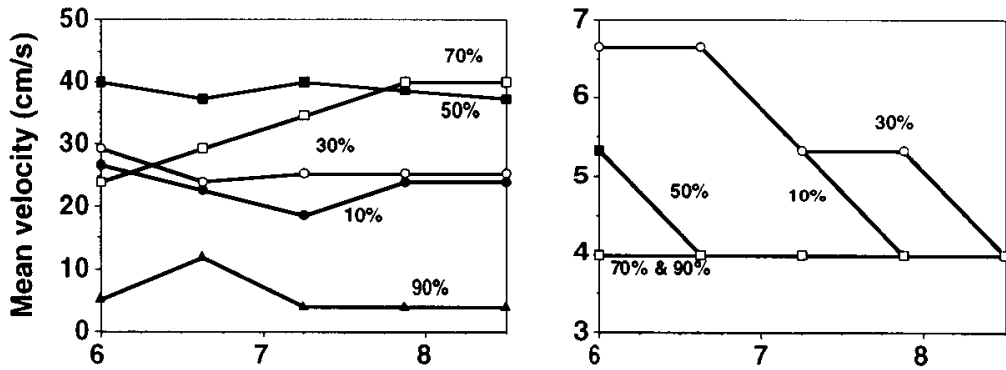

Day $=50$
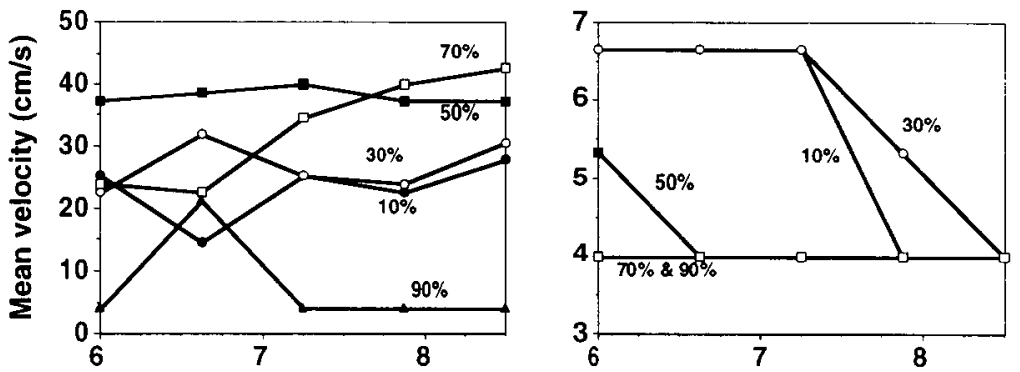

Day $=70$
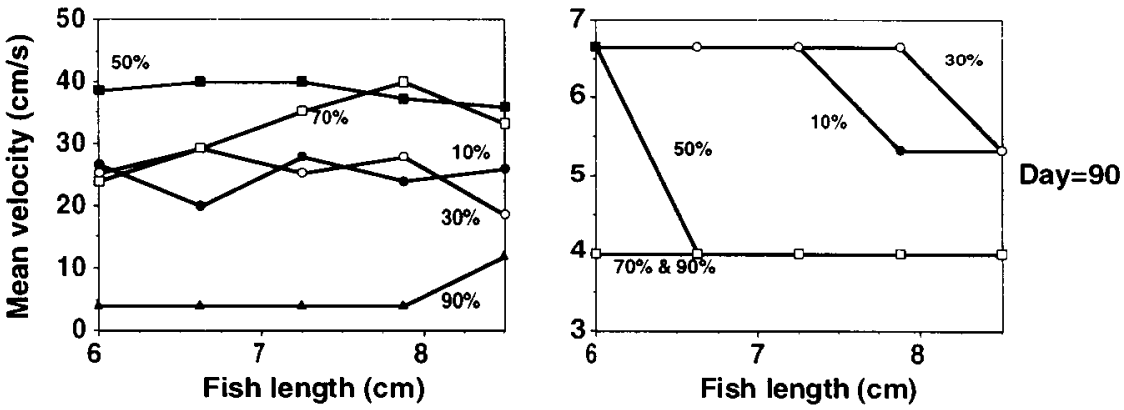
Table 1. Proportion of zooplankton consumed by northern anchovy schools of various diameters.

\begin{tabular}{cllll}
\hline & \multicolumn{5}{c}{ Risk } \\
\cline { 2 - 5 } School diameter $(\mathrm{m})$ & 1 & 2 & 4 & $8-20$ \\
\hline 14.5 & 0.960 & 0.597 & 0.597 & 0.593 \\
28.6 & 0.863 & 0.614 & 0.614 & 0.611 \\
56.2 & 1 & 1 & 1 & 1 \\
110 & 1 & 1 & 1 & 1 \\
217 & 1 & 1 & 1 & 1 \\
\hline
\end{tabular}

Note: Risk refers to how much more risky a zooplankton patch is for a fish than the water surrounding the patch. When risk $=1$, then the fish act as net energy intake rate maximizers (see text).

Fig. 4. Predicted stomach contents of randomly sampled northern anchovy when they are assumed to be either net energy intake rate maximizers or predation sensitive. Risk in the zooplankton patch ranges from equal to the surrounding waters to 8 times greater. When risk is equal, fish behave so as to maximize overall growth rates. The columns are given by their midrange values.
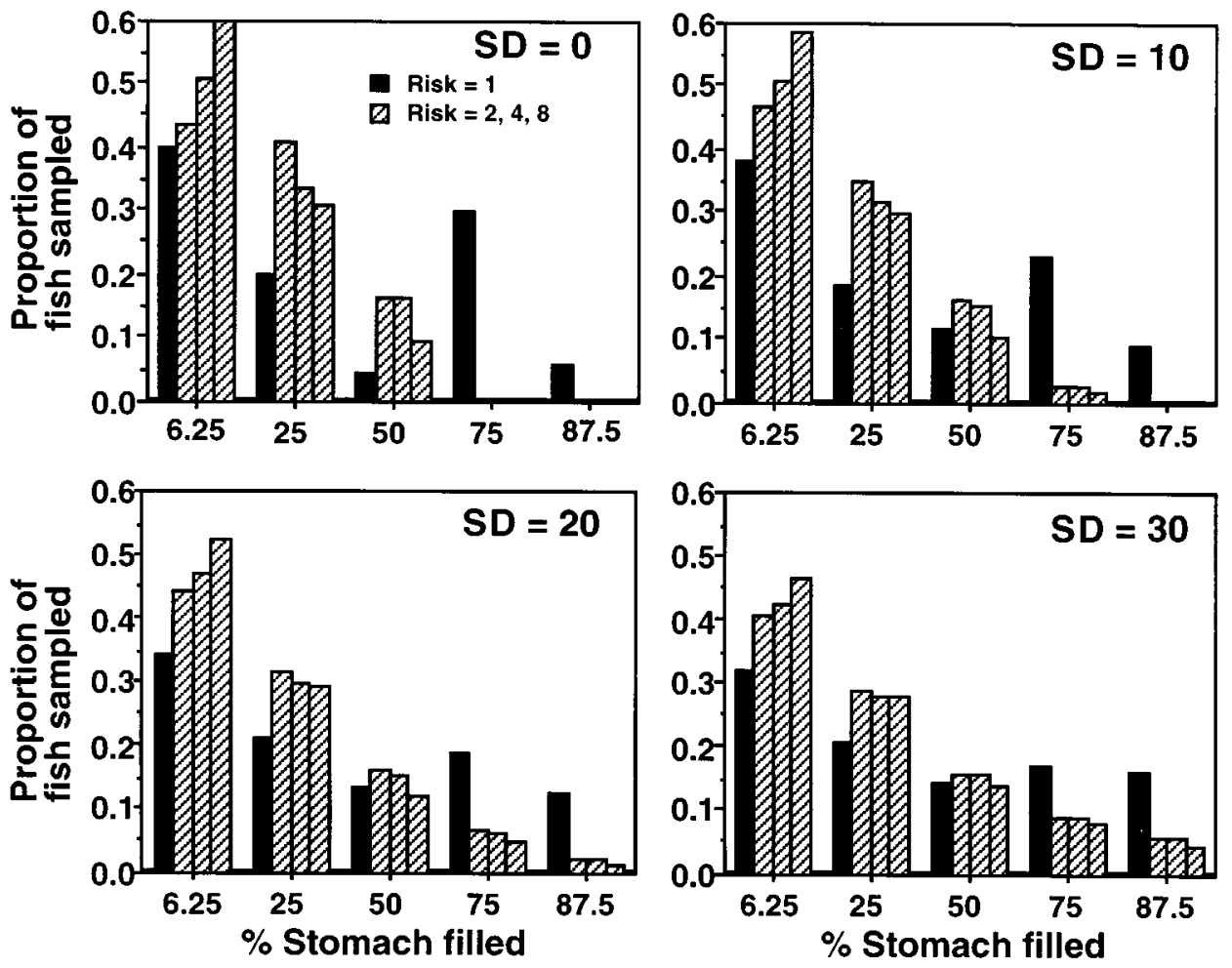

contrast, under an assumption of predation sensitivity, the distributions are always unimodal, with most fish having guts that are $<25 \%$ full. The effect of increasing relative risk in the patch exaggerates this relationship, but qualitatively, the effect is the same. Within-school variability makes the differences less clear, but the patterns still appear distinct.

\section{Discussion}

The results of this model are valuable in two ways: (i) to generate testable predictions and (ii) to identify critical assumptions for which data need to be collected.

\section{Testing predictions}

Gut contents

A population of energy-maximizing fish should show a bimodal distribution in stomach contents, with a significant fraction of the fish having rather full stomachs. In contrast, the assumption of predation risk sensitivity predicts a unimodal distribution, with the large majority of fish having very little in their stomachs at any given time (Fig. 4). Loukashkin (1970) measured the stomach contents of sampled E. mordax from several populations. His estimates of content were divided into five categories: $(i)$ empty or almost empty $(0 \%$ 
Fig. 5. Stomach contents of four populations of northern anchovy sampled by Loukashkin (1970). He categorized stomach fullness as either empty or almost empty, 25\% full, $50 \%$ full, $75 \%$ full, and almost or totally to capacity.

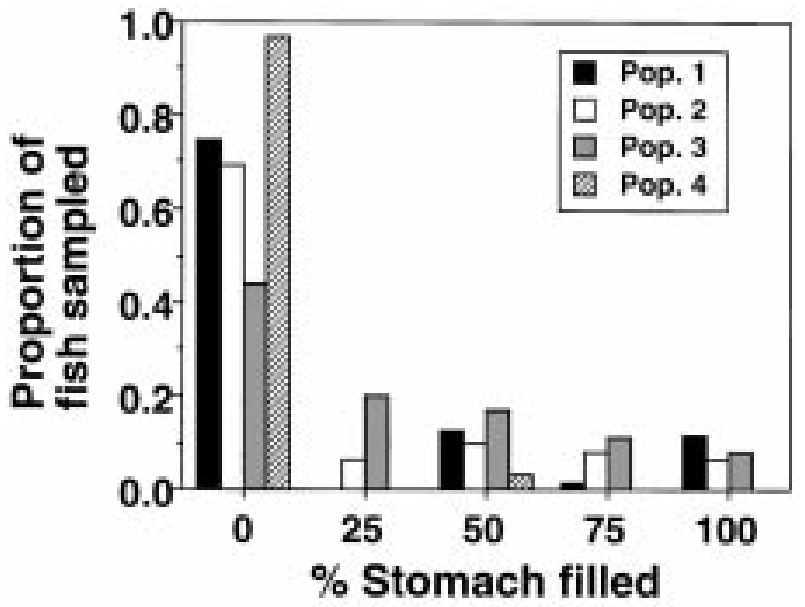

full), (ii) $25 \%$ full, (iii) $50 \%$ full, (iv) $75 \%$ full, and (v) full to almost bursting. From four populations where a large sample was taken, it is clear that most fish had very little in their stomachs, and in only one population (No. 1) was there a suggestion of a bimodal distribution in gut contents (Fig. 5). Therefore, these data are clearly more consistent with the assumption of risk sensitive behavior.

An indirect piece of evidence comes from Arthur (1976), who summarized measurements of feeding incidence (defined as the percentage of fish with food in their stomachs) in clupeoid fish larvae. Larvae are much smaller than the juveniles considered in our models and thus may differ in behavior for size-based reasons. Nevertheless, for several Engraulis species, Arthur (1976) reported feeding incidences rarely in excess of 30\% and often quite a bit lower. Interestingly, Pacific sardine (Sardinops sagax) and jack mackerel (Trachurus symmetricus) larvae of the same size as anchovy larvae and feeding on the same prey items had considerably higher levels of feeding incidence (at times, over $90 \%$ in the mackerel). Sardines born at the same time as anchovies in the same waters show higher growth rates than anchovies, and mackerel grow faster than either sardines or anchovies (Blaxter and Hunter 1982).

\section{Growth rates}

The highest growth rates predicted by our model are physiologically possible for anchovy juveniles. Fish kept in the laboratory and fed ad libitum exhibit growth rates equal to or exceeding our predicted maximal rate (Blaxter and Hunter 1982; Boggs 1991). We can also compare the model's predictions with field data. Butler (1989) sampled E. mordax in the California Current at various times of the year and found a population with a continuously increasing mean size (Fig. 2). These data cannot be considered a true measure of growth rate because if smaller fish are more likely to be eaten, then samples later in the season reflect both growth and differential predation. Therefore, the data are likely to slightly overestimate the true growth rate of the surviving fish. Thus, the predicted growth rate under an assumption of energy maximization seems to far outstrip the rate of fish in the field. In contrast, fish showing risk sensitivity to zooplankton patches that are 2-4 times more risky than the surrounding waters have growth rates very similar to the progression shown in Butler's (1989) samples. This again suggests that anchovies in nature respond to both prey densities and their own predators.

Sudden bursts of apparent accelerated growth have occasionally been observed in natural populations of E. mordax. Fiedler et al. (1986) recorded an increased growth rate (by as much as $0.2 \mathrm{~mm} /$ day over a 2-month period) from the 1982 and 1983 age-classes during the autumn of 1984. As it is unlikely that there could have been an improvement in the food supply at this time of the year, it may be that the anchovies were responding to the withdrawal of exotic, tropical predators such as tropical tunas, skipjack tuna (Katsuwonus pelamis), and yellowfin tuna (Thunnus albacares) at the end of an El Niño cycle. A reduction in the risk associated with feeding would predict increased use of zooplankton patches and thus an increased growth rate.

\section{Swimming speeds and behavior}

The model predicts that the swimming behavior of fish that are energy maximizing or predation risk sensitive will be quite different. Energy-maximizing fish should swim rapidly, and all but the largest schools should rarely stay in one area very long, particularly in the absence of encountering high-density zooplankton patches. In contrast, predationsensitive fish should be observed to swim very rapidly in zooplankton patches and rather slowly between encounters of patches. Schools would be expected to linger in areas even in the absence of zooplankton patches, as long as they are not attracting predators. Such behavior would increase survival in two ways: fish reduce time spent in the more dangerous zooplankton patch, and if anchovies and their predators also follow a Gerritsen-Strickler encounter model (Gerritsen and Strickler 1977), then swimming slowly on the part of the prey (the anchovies in this case) would reduce encounter rates (this latter effect was not considered in the model, but see Swartzman 1991). Furthermore, smaller schools of predationsensitive fish of the same size are predicted to swim more rapidly later in the season. This is likely due to food (i.e., growth) becoming more important to the fish as time passes. For example, a $7-\mathrm{cm}$ fish at day 1 of the model has 270 days in which to reach reproductive size. In contrast, a $7-\mathrm{cm}$ fish at day 90 has only 180 days and thus has to sacrifice safety to increase growth rate.

\section{Composition and movement of fish schools}

Bioenergetically, the cost of swimming is easily offset by foraging gains in the zooplankton, and the per gram costs of swimming decrease with increasing size. Thus, if fish are energy maximizing, all fish should move rapidly at most times so as to encounter more zooplankton patches. If there are any differences in swimming speed, it should be the larger fish that sometimes swim faster between patches than smaller fish (i.e., from a bioenergetic standpoint, swimming is less costly per unit biomass for larger fish). If fish are predation risk sensitive, however, it should be smaller fish that tend to swim faster between patches, especially in smaller schools. Intuitively, this result reflects the trade-off of 
Fig. 6. Combinations of growth rates and the mean IMR for fish that are net energy intake rate maximizers (squares) or predation sensitive (circles). The heavy line is the set of values from a Lefkovitch population matrix that predicts a stable population (Nonacs et al. 1994). Values above and to the left of the line predict declining populations, while values below and to the right predict possibly increasing populations. The open triangle is the predicted combination for predation-sensitive fish in a scenario of climate change (see text) and with zooplankton patches being 4 times riskier than their surrounding waters.

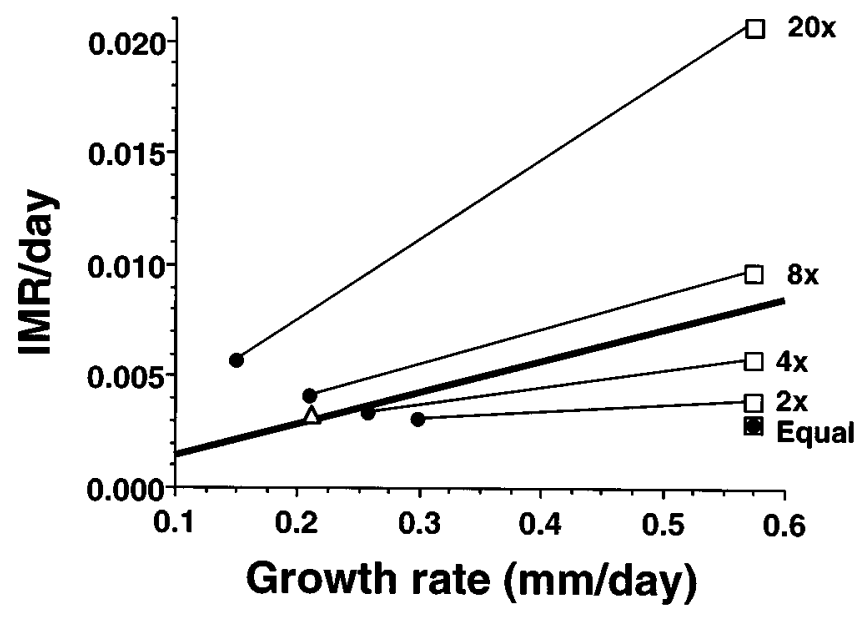

growth versus safety such that faster growth maximizes fitness more for smaller fish than it does for larger fish. Different optimal swimming speeds for different sizes of fish suggest that mixed size schools are not stable for all sizeclasses, and we should see significant size segregation across schools. For example, if fish are predation sensitive, then smaller schools may divide due to their members swimming between patches at different velocities. However, large schools may be more diverse in fish sizes because the optimal velocities are predicted to be minimal for all sizes.

\section{Exploitation of zooplankton patches}

Our model predicts that anchovy behavior can have different consequences for the zooplankton patches. For energymaximizing fish, encountered patches of zooplankton should almost always be completely consumed. Conversely, predation-sensitive fish in smaller schools should leave with perhaps as much as $40 \%$ of the zooplankton still uneaten. To our knowledge, no study has directly examined how long fish stay in zooplankton patches or the state of the patch once the school leaves.

\section{Population and species effects}

It is also possible to gain insight into how the behavior of schools can affect the population dynamics of the species. The life cycle of E. mordax can be divided into nine size-based stages (Smith 1985; Butler et al. 1993). We used a Lefkovitch matrix (Lefkovitch 1965) to predict population growth, stability, or decline based on possible combinations of growth and mortality rates for each stage (see Nonacs et al. 1994 for details). In Fig. 6, these combinations are plotted as the heavy line, where combinations of growth rate and average daily IMR for the late juvenile life stage to the left and above the line result in declining populations and combinations to the right and below can result in increasing populations. The combination of growth rates and IMR's with an assumption of predation sensitivity plot into the region of population growth until the risk in the zooplankton patches more than exceeds 4 times that of the surrounding water. The model predicts that as the patches get relatively more risky, fish sacrifice growth rate more than survivorship (i.e., predation risk sensitivity increases). The exact location of the growth rate/IMR points from our model vis-à-vis the prediction from the Lefkovitch population model partially depends on the assumption of the baseline mortality rate of a fish while not in a zooplankton patch (a maximum mortality rate of $0.003 /$ day). A proportionally lower baseline estimate would move all the points down a similar proportion on the $y$-axis. Conversely, a higher estimate would move them up. Therefore, in Fig. 6, it is the location of the points relative to each other that is likely the more robust result rather than their absolute position in relation to the population model.

Energy-maximizing fish do not sacrifice growth rate and thus incur higher IMR's as the relative risk of the zooplankton patch increases (squares in Fig. 6). Under our assumptions of predation risk, population growth with energy-maximizing fish would be positive until the risk in the zooplankton patches is between 4 and 8 times greater than in the surrounding waters. Thus, at the population level, multiple strategies may co-occur in the same habitat if zooplankton patches are not that much riskier. For example, anchovies, sardines, and mackerel may coexist in the same waters even if as larvae and juveniles they respond differently to predators. However, if patches are much riskier (e.g., 20 times), then the cost of ignoring the predation becomes much more severe and energy-maximizing populations may be much less likely to persist than predation-sensitive ones.

\section{Implications for future research}

Our model relies on a combination of data and assumptions. While the assumptions we make are to our knowledge the most reflective of natural conditions, it is also clear that aspects of the biology of E. mordax need to be better understood, particularly predation risk, school formation and dynamics, comparison with other species of schooling fish, and environmental stability.

\section{Predation risk}

First and foremost, it would be particularly valuable to determine whether fish are more at risk while feeding in zooplankton patches than when swimming between them. If zooplankton patches are not more risky than the water between, or in fact are safer, then there is no trade-off between foraging gain and avoiding predation risk and we would predict that all fish should act like energy maximizers. Second, we need to have more accurate size-dependent predation rates for both the behavioral and population models. For example, Nonacs et al. (1994) examined various assumptions about the predation risk functions used in these models and found that behavior was strongly affected by how rapidly growth reduced predation risk. Not surprisingly, the more likely fish were to "outgrow" their predators, the more closely they behaved like net energy rate maximizers. Therefore, anchovy behavior should be affected by the relative attack rates of predators that they cannot outgrow (e.g., seabirds, dolphins) and those that 
Fig. 7. Predicted growth rates of northern anchovy under present-day conditions (solid lines) and under a scenario where zooplankton patches are 50\% smaller and 50\% further apart (broken lines). Fish are assumed to be either net energy intake rate maximizers or predation sensitive in a scenario where the zooplankton patches have 4 times the predation risk of the surrounding waters. The heavy gray lines are the mean size of anchovy juveniles caught in the field as the season progresses in a non-El Niño year (top line) and in an El-Niño year (Butler 1989).

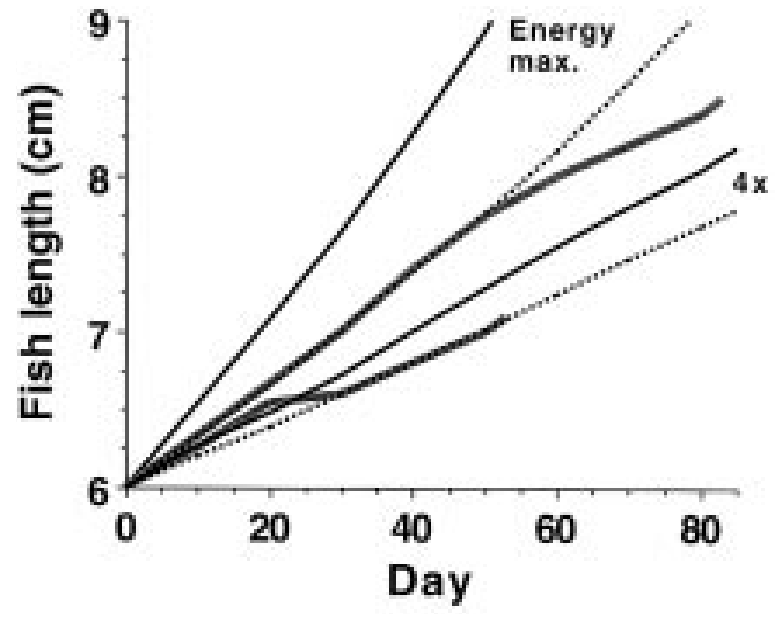

they can outgrow (e.g., smaller piscivores such as adult anchovies). Growth rate / predation risk trade-offs could be adapted to the predominant type of search and tactical predation experienced by the fish. Sustained predation by one suite of predators may result in tactical adaptation in the schooling behavior of their prey to the nature of the attack (Neill and Cullen 1974). For example, fish schools continually attacked from the air by visual predators may compact and move to greater depths, or schools attacked by acoustically guided predators may move towards the surface where acoustic returns can be more ambiguous. Also, if attacks tend to correlate with specific ambient characteristics (e.g., day versus night, or in cloudy rather than clear water), appropriate avoidance behaviors could be expected to evolve.

\section{School formation and dynamics}

Habitat richness and the costs of swimming must combine to set a maximum school size beyond which anchovies would be in a negative energy balance. Applying our bioenergetics model to observed school sizes argues that at least $25 \%$ of the anchovy population is in a negative energy balance. This suggests that the largest schools form for reasons besides foraging.

Our model assumed that predation risk was independent of school size. However, if the per capita mortality rate of fish declines with increasing school size, large schools may be safer for fish and may be particularly favored by fish that have had recent bouts of good foraging. Conversely, it is possible that very large schools are especially easy for predators to find, and thus the largest schools might provide neither increased foraging nor increased safety. The question of whether schools are effective as antipredator devices is quite complicated and attack abatement from predators may be a function of both avoiding predators and diluting individual risk (Turner and Pitcher 1986). Very large schools may also form spontaneously for nonadaptive reasons, such as coalescing into a single school when encountering each other. Thus, large schools might be transitory and more likely to occur in waters where schools are likely to intersect each other. Overall, the pattern of school formation and breakup in E. mordax could be very important to understanding the benefits of the schooling.

\section{Other species of schooling fish}

Anchovies, sardines, and mackerel are all found off the California coast and as juveniles feed on the same prey items, but exhibit different growth rates. Our model would predict both higher growth rates and higher mortality rates for mackerel and sardines if their behavior were less predation risk sensitive than that of anchovies. Therefore, comparative studies are needed of foraging behavior of each species. In one such study (Holliday 1977), one anchovy school and two jack mackerel schools were followed for a distance of $1 \mathrm{~km}$. Overall, the mackerel swam faster than the anchovies, which would be consistent with net energy rate maximization in mackerel.

\section{Environmental stability}

We repeated model simulations with a scenario of a poorer environment in which zooplankton patch size was decreased by $50 \%$ and the distance between patches was increased by $50 \%$. Even with an assumption of a rather substantial decline in large zooplankton, maximal possible growth rates can still match the growth rate inferred from Butler's (1989) samples (Fig. 7). It is interesting to note that growth rates observed in an environmentally stressful El Niño year were considerably reduced and they closely resemble the predation-sensitive prediction with a habitat affected by climate change (Fiedler et al. 1986).

Predation-sensitive fish in environments where zooplankton patches are 4 times riskier than the surrounding waters still express a combination of growth rate and IMR that is very close to values predicted for a stable population (triangle in Fig. 6). The largest bioenergetically economic schools in this changed environment would have diameters of 50 or $59 \mathrm{~m}$ for $6-$ or $8.5-\mathrm{cm}$ fish, respectively, so that in relation to present-day school sizes, anchovies will be in net negative energy balance about $50 \%$ of the time. This would predict that if school size is directly affected by fish hunger levels, poorer environments should result in smaller schools. For species that need rapid growth rates to reach breeding size in a short period of time (e.g., sardines and jack mackerel, see above), less available food could have much more severe population consequences, either through increased mortality rates or increased time to maturation.

Therefore, E. mordax populations may not be severely affected by dramatic changes in their zooplankton prey, given that all other variables remain constant. However, it is unlikely that this last assumption holds. For example, changes in zooplankton patches could increase predation rates if predators accumulate at these patches, or could decrease predation rates if predators have more difficulty in encountering these patches than do anchovy schools. The former would decrease anchovy populations and the latter would increase them. If in a poorer environment, fish tend to form smaller schools, then, 
at least as far as energetic limitations are concerned, growth rates would be very much less affected than our model predicts. On the other hand, if the new distributions of zooplankton patches tend to concentrate fish into larger schools, then growth rates would be even more reduced than our model now predicts. Also, a change in the average size of fish schools could have a significant impact on the cost-effectiveness of fishers harvesting those schools. In sum, if environmental change brings a correlated change in anchovy behavior or the behavior of anchovy predators, the population-level effects could be dramatic and unpredictable from our current state of knowledge. Therefore, it may be very important to observe behavioral responses to varied and changing environmental conditions.

\section{Acknowledgments}

We thank A. Bouskila and B. Luttbeg for their help with designing the models in their larval life stages and E.M. DeBlois, S. Gilboa, and an anonymous reviewer for many helpful comments on the manuscript. This work was supported by NSF grant OCE 90-16895 to M. Mangel. This is contribution 100 of the U.S. GLOBEC program, funded jointly by NOAA and NSF.

\section{References}

Abrahams, M.V., and Dill, L.M. 1989. A determination of the energetic equivalence of the risk of predation. Ecology, 70: 999-1007.

Arthur, D.K. 1976. Food and feeding of larvae of three fishes occurring in the California Current, Sardinops sagax, Engraulis mordax, and Trachurus symmetricus. Fish. Bull. U.S. 74: 517529.

Blaxter, J.H.S., and Hunter, J.R. 1982. The biology of the clupeoid fishes. In Advances in marine biology. Vol. 20. Edited by J.H.S. Blaxter, F.S. Russell, and R. Yonge. Academic Press, New York.

Boggs, C.H. 1991. Bioenergetics and growth of northern anchovy Engraulis mordax. Fish. Bull. U.S. 89: 555-566.

Brock, V.E., and Riffenburgh, R.H. 1960. Fish schooling: a possible factor in reducing predation. J. Cons. Cons. Int. Explor. Mer, 25: $307-317$

Butler, J.L. 1989. Growth during the larval and juvenile stages of the northern anchovy, Engraulis mordax, in the California current during 1980-84. Fish. Bull. U.S. 87: 645-652.

Butler, J.L., Smith, P.E., and Lo, N.C.H. 1993. The effect of natural variability of life-history parameters on anchovy and sardine population growth. Calif. Coop. Oceanic Fish. Invest. Rep. 34: 5562.

DeBlois, E.M., and Rose, G.A. 1995. Effect of foraging activity on the shoal structure of cod (Gadus morhua). Can. J. Fish. Aquat. Sci. 52: 2377-2387.

DeBlois, E.M., and Rose, G.A. 1996. Cross-shoal variability in the feeding habits of migrating Atlantic cod (Gadus morhua). Oecologia (Heidelb.), 108: 192-196.

Dill, L.M., and Fraser, A.H.G. 1984. Risk of predation and the feeding behavior of juvenile coho salmon (Oncorhynchus kisutch) Behav. Ecol. Sociobiol. 16: 65-71.

Duffy, D.C., and Wissel, C. 1988. Models of fish school size in relation to environmental productivity. Ecol. Model. 40: 201-211.

Eshel, I. 1978. On a prey-predator nonzero-sum game and the evolution of gregarious behavior of evasive prey. Am. Nat. 112: 787 795.

Fiedler, P.C., Methot, R.D., and Hewitt, R.P. 1986. Effects of Cali- fornia El Niño 1982-1984 on the northern anchovy. J. Mar. Res. 44: 317-338.

Fraser, D.F., and Gilliam, J.F. 1992. Nonlethal impacts of predator invasion: facultative suppression of growth and reproduction. Ecology, 73: 959-970.

Gates, D.M. 1993. Climate change and its biological consequences. Sinauer Associates, Sunderland, Mass.

Gerritsen, J., and Strickler, J.R. 1977. Encounter probabilities and community structure in zooplankton: a mathematical model. J. Fish. Res. Board Can. 34: 73-82.

Graves, J. 1977. Photographic method for measuring spacing and density within pelagic fish schools at sea. Fish. Bull. U.S. 75: 230-234.

Holliday, D.V. 1977. Two applications of the doppler effect in the study of fish schools. Rapp. P.-v. Réun. Cons. Int. Explor. Mer, 170: $21-30$.

Hunter, J.R., and Leong, R. 1981. The spawning energetics of female northern anchovy, Engraulis mordax. Fish. Bull. U.S. 79: $215-229$.

Koslow, J.A. 1981. Feeding selectivity of schools of northern anchovy Engraulis mordax, in the Southern California Bight. Fish. Bull. U.S. 79: 131-142.

Krause, J. 1993. The relationship between foraging and shoal position in a mixed shoal of roach (Rutilus rutilus) and chub (Leuciscus cephalus): a field study. Oecologia (Heidelb.), 93: 356359.

Lefkovitch, L.P. 1965. The study of population growth in organisms grouped by stages. Biometrics, 21: 1-18.

Loukashkin, A.S. 1970. On the diet and feeding behavior of the northern anchovy, Engraulis mordax (Girard). Proc. Calif. Acad. Sci. 37: 419-458.

Mangel, M., and Clark, C.W. 1988. Dynamic modeling in behavioral ecology. Princeton University, Princeton, N.J.

Neill, S.R. St. J., and Cullen, J.M. 1974. Experiments on whether schooling by their prey affects the hunting behaviour of cephalopods and fish predators. J. Zool. (Lond.), 172: 549-569.

Nonacs, P., Smith, P.E., Bouskila, A., and Luttbeg, B. 1994. Modeling the behavior of the northern anchovy, Engraulis mordax, as a schooling predator exploiting patchy prey. Deep-Sea Res. 41: $147-169$.

Smith, P.E. 1981. Fisheries on coastal pelagic fish. In Marine fish larvae: morphology, ecology, and relation to fisheries. Edited by R. Lasker. University of Washington, Seattle, Wash. pp. 1-32.

Smith, P.E. 1985. Year-class strength and survival of O-group clupeoids. In Proceedings of the Symposium on the Biological Characteristics of Herring and Their Implications for Management. Edited by J.R. Brett. Can. J. Fish. Aquat. Sci. 42(Suppl. 1): 6992.

Smith, P.E., Ohman, M.D., and Eber, L.E. 1989. Analysis of the patterns of zooplankton aggregations from an acoustic doppler current profiler. Calif. Coop. Oceanic Fish. Invest. Rep. 30: 88-103.

Star, J.L., and Mullin, M.M. 1981. Zooplanktonic assemblages in three areas of the North Pacific as revealed by continuous horizontal transects. Deep-Sea Res. 28: 1303-1322.

Stephens, D.W., and Krebs, J.R. 1986. Foraging theory. Princeton University, Princeton, N.J.

Swartzman, G. 1991. Fish school formation and maintenance: a random encounter model. Ecol. Model. 56: 63-80.

Turner, G.F., and Pitcher, T.J. 1986. Attack abatement: a model for group protection by combined avoidance and dilution. Am. Nat. 128: $228-240$.

Werner, E.E., Gilliam, J.F., Hall, D.J., and Mittelbach, G.G. 1983. An experimental test of the effects of predation risk on habitat use in fish. Ecology, 64: 1540-1548. 